\title{
Recruitment of a Neuronal Ensemble in the Central Nucleus of the Amygdala Is Required for Alcohol Dependence
}

\author{
@Giordano de Guglielmo, ${ }^{1}$ Elena Crawford, ${ }^{1}$ Sarah Kim, ${ }^{1}$ Leandro F. Vendruscolo, ${ }^{1}$ @Bruce T. Hope, ${ }^{2}$ \\ Dolly Brennan, ${ }^{1}$ Maury Cole, ${ }^{1}$ George F. Koob, ${ }^{1}$ and ${ }^{-}$Olivier George ${ }^{1}$ \\ ${ }^{1}$ Committee on the Neurobiology of Addictive Disorders, The Scripps Research Institute, La Jolla, California 92037, and 2National Institute on Drug Abuse, \\ Intramural Research Program, National Institutes of Health, Baltimore, Maryland 21224
}

\begin{abstract}
Abstinence from alcohol is associated with the recruitment of neurons in the central nucleus of the amygdala (CeA) in nondependent rats that binge drink alcohol and in alcohol-dependent rats. However, whether the recruitment of this neuronal ensemble in the CeA is causally related to excessive alcohol drinking or if it represents a consequence of excessive drinking remains unknown. We tested the hypothesis that the recruitment of a neuronal ensemble in the CeA during abstinence is required for excessive alcohol drinking in nondependent rats that binge drink alcohol and in alcohol-dependent rats. We found that inactivation of the CeA neuronal ensemble during abstinence significantly decreased alcohol drinking in both groups. In nondependent rats, the decrease in alcohol intake was transient and returned to normal the day after the injection. In dependent rats, inactivation of the neuronal ensemble with Daun02 produced a long-term decrease in alcohol drinking. Moreover, we observed a significant reduction of somatic withdrawal signs in dependent animals that were injected with Daun02 in the CeA. These results indicate that the recruitment of a neuronal ensemble in the CeA during abstinence from alcohol is causally related to excessive alcohol drinking in alcohol-dependent rats, whereas a similar neuronal ensemble only partially contributed to alcohol-binge-like drinking in nondependent rats. These results identify a critical neurobiological mechanism that may be required for the transition to alcohol dependence, suggesting that focusing on the neuronal ensemble in the CeA may lead to a better understanding of the etiology of alcohol use disorders and improve medication development.
\end{abstract}

Key words: addiction; alcohol; CeA; Daun02; dependence; neuronal ensembles

\section{Significance Statement}

Alcohol dependence recruits neurons in the central nucleus of the amygdala (CeA). Here, we found that inactivation of a specific dependence-induced neuronal ensemble in the CeA reversed excessive alcohol drinking and somatic signs of alcohol dependence in rats. These results identify a critical neurobiological mechanism that is required for alcohol dependence, suggesting that targeting dependence neuronal ensembles may lead to a better understanding of the etiology of alcohol use disorders, with implications for diagnosis, prevention, and treatment.

\section{Introduction}

Alcohol binge drinking and alcoholism lead to 3.3 million deaths worldwide annually, but treatments are limited (Johnson, 2008). Maladaptive behavioral patterns toward alcohol (e.g., compulsive

Received April 27, 2016; revised June 22, 2016; accepted July 11, 2016.

Author contributions: G.d.G. and 0.G. designed the experiments; G.d.G., E.C., S.K., M.B., and M.C. performed the experiments; G.d.G., L.F.V., and 0.G. analyzed the data; G.d.G., G.F.K. and 0.G. wrote the paper.

This is publication number 29397 from The Scripps Research Institute.

This work was supported by the National Institutes of Health (Grants AA006420, AA020608, and AA022977 to 0.G.), the National Institute on Drug Abuse Intramural Research Program (B.T.H.), and the Pearson Center for Alcohol and Addiction Research.

The authors declare no competing financial interests.

Correspondence should be addressed to Dr. Olivier George, Committee on the Neurobiology of Addictive

Disorders, The Scripps Research Institute, 10550 North Torrey Pines Road, SP30-2400, La Jolla, CA 92037.

E-mail: ogeorge@scripps.edu.

DOI:10.1523/JNEUROSCI.1395-16.2016

Copyright $(2016$ the authors $\quad 0270-6474 / 16 / 369446-08 \$ 15.00 / 0$ drinking) have been hypothesized to result from the lasting overactivation of specific neuronal ensembles (Hebb, 1949) in the extended amygdala (George et al., 2012; Lee et al., 2015) that mediate the negative emotional states of alcohol withdrawal (Koob et al., 2014) and encode memories and motivation that are associated with alcohol-related cues (Barak et al., 2013). Numerous studies have identified a key role for the central nucleus of the amygdala (CeA) in alcohol drinking and alcohol dependence (Wrase et al., 2008; Koob, 2009; Koob and Volkow, 2010; Gilpin et al., 2015). Multiple neuropeptide and neuromodulator systems appear to be dysregulated in alcohol dependence and they appear to converge on GABA circuitry in the CeA to produce excessive alcohol drinking and the negative emotional symptoms of alcohol abstinence (Roberto et al., 2004; Weiner and Valenzuela, 2006; Roberto et al., 2010; Gilpin et al., 2015). However, it is unclear whether the CeA as a whole is critical for the manifestation of alcohol dependence or if a discrete popula- 

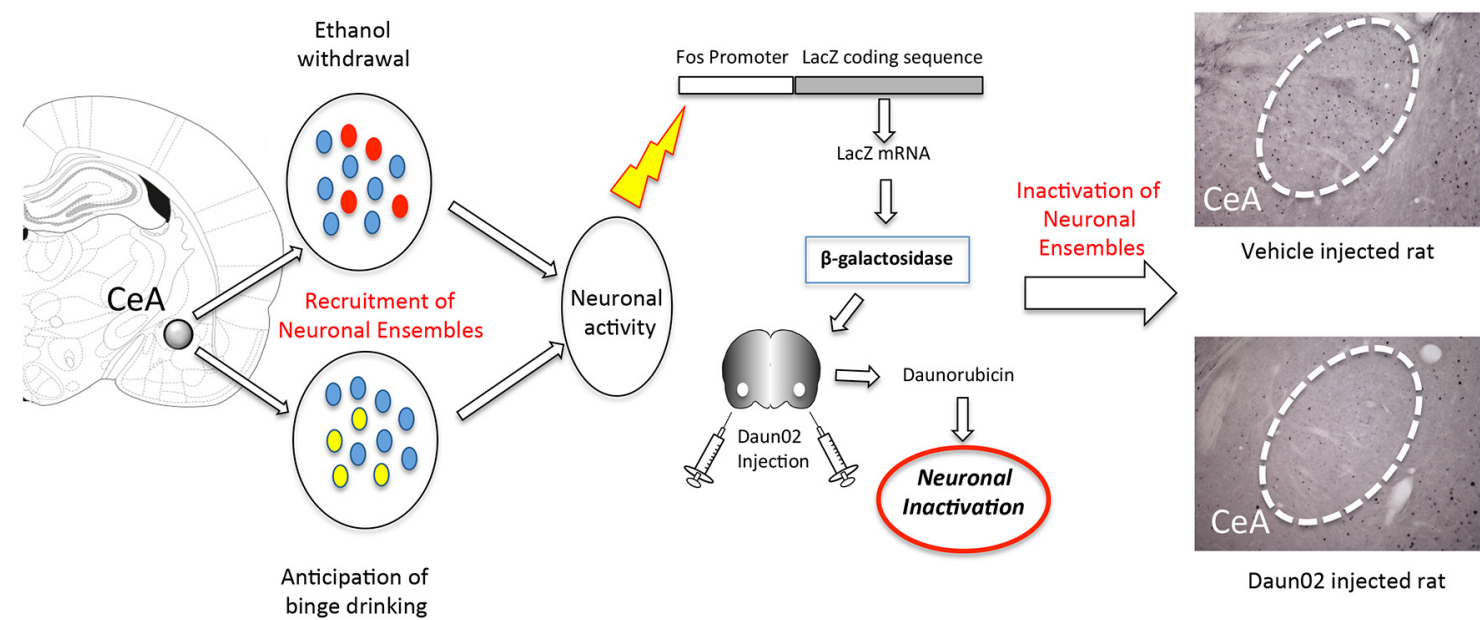

Daun02 injected rat

Figure 1. Daun02 inactivation method. The Fos-LacZ transgene in the transgenic rats contains a Fos promoter that regulates transcription of the LacZ coding sequence. Withdrawal from alcohol induces Fos expression and subsequently activates the c-fos promoter. As a result, the expression of lacZ mRNA and its protein product, $\beta$-galactosidase, is increased in these strongly activated neurons, but not in the surrounding majority of neurons. The prodrug Daun02 is injected into the CeA and initially inactive. However, $\beta$-galactosidase catalyzes Daun02 to the active product daunorubicin, which induces apoptosis and cell death only in those neurons that were activated strongly enough during withdrawal to induce $\beta$-galactosidase.

tion of neurons in the CeA is required for excessive alcohol drinking. A neuronal ensemble that is recruited in the anticipation of alcohol binge drinking was identified recently in the CeA (George et al., 2012). In this work, discrete populations of Fos-positive neurons that are distributed throughout the brain were observed during abstinence from alcohol drinking. The Fos-positive neuronal population in the CeA was one of the only ensembles that was only observed in rats with a history of escalation of alcohol drinking (with intermittent access to alcohol) and not in rats that presented stable alcohol drinking (with continuous access to alcohol). These results strongly suggested that a binge-drinking neuronal ensemble in the CeA may encode the excessive motivation for alcohol that is observed in rats with a history of alcohol binge drinking. However, causal evidence is required to validate this hypothesis. Moreover, it is unknown whether a similar neuronal ensemble can be identified in the CeA in dependent rats and if this hypothetical dependence neuronal ensemble is required for dependence-induced drinking and the emergence of withdrawal signs of dependence in rats. In the present study, we tested the hypothesis that there are specific neuronal ensembles ("abstinence neuronal ensembles") that are required for alcoholbinge-like drinking and dependence-induced drinking. We further tested the hypothesis that these neuronal ensembles play a causal role in alcohol drinking using the Daun02 inactivation technique (Fig. 1). This approach allows the specific inactivation of neuronal ensembles that are recruited by a specific event or state without affecting either the surrounding nonactivated neurons or neurons that are activated by other stimuli or events. The Daun02 inactivation procedure uses Fos-LacZ transgenic rats that express $\beta$-galactosidase ( $\beta$-gal) under the control of the cfos promoter (Koya et al., 2009). $\beta$-gal is induced only in strongly activated Fos + neurons and not in surrounding nonactivated (Fos-) or weakly activated neurons (Cruz et al., 2013). $\beta$-gal in these strongly activated neurons converts the prodrug Daun02 to daunorubicin that initially reduces neuronal activity (Santone et al., 1986; Engeln et al., 2016) and then cell death by apoptosis (Pfarr et al., 2015). Therefore, the Daun02 inactivation procedure provides a way to test whether a specific neuronal ensemble is required for a specific behavior.

\section{Materials and Methods}

Subjects

Adult male Fos-LacZ transgenic rats, weighing 200-225 g at the beginning of the experiments, were housed in groups of two per cage (self- administration groups) or single housed (two-bottle choice) in a temperature-controlled $\left(22^{\circ} \mathrm{C}\right.$ ) vivarium on a $12 \mathrm{~h} / 12 \mathrm{~h}$ light/dark cycle (lights on at 10:00 P.M.) with ad libitum access to food and water. All of the behavioral tests were conducted during the dark phase of the light/ dark cycle. All of the procedures adhered to the National Institutes of Health's Guide for the Care and Use of Laboratory Animals and were approved by the Institutional Animal Care and Use Committee of the Scripps Research Institute.

\section{Intermittent access to $20 \%$ ethanol in a two-bottle-choice} drinking paradigm

Two $100 \mathrm{ml}$ graduated plastic bottles with stainless-steel drinking spouts were inserted through two grommets in front of each cage $15 \mathrm{~min}$ after the lights were turned off in the reversed light/dark cycle room. The rats had ad libitum access to food and water every day and access to $20 \%$ alcohol on Monday, Wednesday, and Friday. Both bottles were weighed $24 \mathrm{~h}$ after the fluids were presented and measurements were taken to the nearest gram. The position of the bottles was switched every other day to avoid side preference. The body weight of each rat was measured daily Monday through Friday to calculate the grams of ethanol intake per kilogram of body weight.

At the beginning of the experiment, the animals were given continuous access to one bottle that contained a $20 \%$ alcohol solution and one bottle that contained water. No initiation procedures were used before the first alcohol drinking session. Once a stable baseline of alcohol intake was reached, the rats were subjected to an intermittent-access, 20\% alcoholdrinking paradigm (i.e., Monday, Wednesday, and Friday).

\section{Operant self-administration}

Self-administration sessions were conducted in standard operant conditioning chambers (Med Associates). For the alcohol self-administration studies, the animals were first trained to self-administer $10 \%(\mathrm{w} / \mathrm{v})$ alcohol and water solutions until a stable response pattern ( $20 \pm 5$ rewards) was maintained. The rats were subjected to an overnight session in the operant chambers with access to one lever (right lever) that delivered water (fixed-ratio 1, FR1). Food was available ad libitum during this training. After $1 \mathrm{~d}$ off, the rats were subjected to a $2 \mathrm{~h}$ session (FR1) for $1 \mathrm{~d}$ and a $1 \mathrm{~h}$ session (FR1) the next day, with 1 lever delivering alcohol (right lever). All of the subsequent alcohol self-administration sessions lasted $30 \mathrm{~min}$. The rats were allowed to self-administer a 10\% (w/v) alcohol solution (right lever) and water (left lever) on an FR1 schedule of reinforcement (i.e., each operant response was reinforced with $0.1 \mathrm{ml}$ of the solution). For the saccharin self-administration study, the rats underwent daily 30 min FR1 sessions. Responses on the right lever resulted in the delivery of $0.1 \mathrm{ml}$ of saccharin $(0.04 \%, \mathrm{w} / \mathrm{v})$. Lever presses on the left 
lever delivered $0.1 \mathrm{ml}$ of water. This procedure lasted $13 \mathrm{~d}$ until a stable baseline of intake was reached.

\section{Alcohol vapor chambers}

The rats were trained previously to self-administer alcohol in the operant chambers. Once a stable baseline of alcohol intake was reached, the rats were made dependent by chronic intermittent exposure to alcohol vapors. They underwent cycles of $14 \mathrm{~h}$ on (blood alcohol levels during vapor exposure ranged between 150 and $250 \mathrm{mg} \%$ ) and $10 \mathrm{~h}$ off, during which behavioral testing for acute withdrawal occurred (i.e., $6-8 \mathrm{~h}$ after the vapor was turned off, when brain and blood alcohol levels are negligible). In this model, rats exhibit somatic and motivational signs of withdrawal (Vendruscolo and Roberts, 2014).

\section{Operant self-administration and withdrawal scores during alcohol vapor exposure}

Behavioral testing occurred three times per week. The rats were tested for alcohol or saccharin (and water) self-administration on an FR1 schedule of reinforcement in $30 \mathrm{~min}$ sessions. Behavioral signs of withdrawal were measured using a rating scale adapted from a previous study (Macey et al., 1996) and included ventromedial limb retraction, irritability to touch (vocalization), tail rigidity, abnormal gait, and body tremors. Each sign was given a score of $0-2$, based on the following severity scale: $0=$ no sign, $1=$ moderate, and $2=$ severe. The sum of the 4 observation scores $(0-8)$ was used as an operational measure of withdrawal severity. The withdrawal ratings were scored by an operator blinded to the treatments.

\section{Intracranial surgery}

For intracranial surgery, the animals were anesthetized with isoflurane. To reach the CeA, guide cannulas were implanted bilaterally using the following coordinates with reference to bregma: anterior/posterior, -2.6 $\mathrm{mm}$; medial/lateral, $\pm 4.2 \mathrm{~mm}$; and dorsal/ventral, $-6.1 \mathrm{~mm}$. The animals were allowed to recover for 1 week after surgery.

\section{Drugs}

For intracranial injections, Daun02 was dissolved in a vehicle that consisted of $90 \%$ artificial CSF, 5\% dimethylsulfoxide, and 5\% Tween 80 and injected bilaterally in the CeA at a concentration of $2 \mu \mathrm{g} / 0.5 \mu \mathrm{l} / \mathrm{site}$ through a stainless-steel injector that was $2 \mathrm{~mm}$ longer than the guide cannula so that its tip protruded into the area.

\section{Immunohistochemistry}

At the end of the experiments, the rats were deeply anesthetized with pentobarbital $8 \mathrm{~h}$ into withdrawal (self-administration studies) or $45 \mathrm{~min}$ after the Daun02 injection (2-bottle choice experiment) and perfused with $100 \mathrm{ml}$ of PBS followed by $400 \mathrm{ml}$ of $4 \%$ paraformaldehyde. The brains were postfixed in paraformaldehyde overnight and transferred to $30 \%$ sucrose in $\mathrm{PBS} / 0.1 \%$ azide solution at $4^{\circ} \mathrm{C}$ for $2-3 \mathrm{~d}$. Brains were frozen in powdered dry ice and sectioned on a cryostat. Coronal sections were cut $40 \mu \mathrm{m}$ thick between bregma +4.2 and $-6.48 \mathrm{~mm}$ (Paxinos and Watson, 2005) and collected free floating in PBS/0.1\% azide solution. After three washes in PBS, the sections were incubated in $1 \%$ hydrogen peroxide/PBS (to quench endogenous peroxidase activity), rinsed 3 times in PBS, and blocked for $60 \mathrm{~min}$ in PBS that contained $0.3 \%$ Triton $\mathrm{X}-100,1 \mathrm{mg} / \mathrm{ml}$ bovine serum albumin, and $5 \%$ normal donkey serum. Sections were incubated for $24 \mathrm{~h}$ at $4^{\circ} \mathrm{C}$ with a rabbit monoclonal antiFos antibody (Cell Signaling Technologies \#2250) diluted 1:1000 in PBS/ $0.5 \%$ Tween 20 and $5 \%$ normal donkey serum. The sections were washed again with PBS and incubated for $1 \mathrm{~h}$ in undiluted Rabbit ImmPress HRP reagent (Vector Laboratories). After washing in PBS, the sections were developed for 2-6 min in peroxidase DAB substrate (Vector Laboratories) enhanced with nickel chloride. After rinses in PBS, the sections were mounted onto coated slides (Super Frost Plus; Fisher), air dried, dehydrated through a graded series of alcohol, cleared with Citrasolv (Fisher Scientific), and coverslipped with DPX (Sigma-Aldrich).

Quantitative analysis to obtain unbiased estimates of the total number of Fos + cell bodies was performed on a Zeiss Axiophot Microscope equipped with MicroBrightField Stereo Investigator software, a threeaxis Mac 5000 motorized stage (Ludl Electronics), a Q Imaging Retiga 2000R color digital camera, and a PCI color frame grabber.
Three sections were bilaterally analyzed for each rat. Live video images were used to draw contours (at $5 \times$ magnification) to delineate the CeA. After determining the mounted section thickness and $Z$-plane values, an optical fractionator probe was used to determine the number of positive neurons within the CeA contours. Briefly, a counting frame of appropriate dimensions, denoting forbidden and nonforbidden boundaries, was superimposed on the video monitor and Fos + cells were counted at $20 \times$ magnification. Cells were identified as neurons based on standard morphology and only neurons with a focused nucleus within the nonforbidden regions of the counting frame were counted. Counts from all images from each rat were averaged so that each rat was an $n$ of 1 .

\section{Experimental procedures}

Experiment 1. Effect of inactivation of CeA neuronal ensembles in nondependent rats subjected to intermittent access to $20 \%$ ethanol. Fos LacZ transgenic rats $(n=21)$ were given continuous access to $20 \%$ ethanol and water. When a stable baseline of ethanol intake was reached, they were moved to intermittent access as described above. Once alcohol escalation was established, the animals underwent stereotaxic surgery for bilateral intra-CeA injections. After 1 week of recovery, the rats were reexposed to intermittent access to restore their previous baseline levels of ethanol intake. At this point, the animals were divided into 2 groups that were matched according to drinking levels and bilaterally injected with Daun02 $(2 \mu \mathrm{g} / 0.5 \mu \mathrm{l} / \mathrm{site})$ or its vehicle $90 \mathrm{~min}$ before having access to ethanol and water. Ethanol and water intake were recorded in five ethanol-drinking sessions. On day 11 (see Fig. $1 A$ ), the animals were injected again with Daun02 and transcardially perfused 90 min later, and their brains were collected for immunohistochemical analysis.

Experiment 2. Effect of inactivation of CeA neuronal ensembles in ethanol-dependent rats. Fos LacZ transgenic rats $(n=17)$ were trained to self-administer $10 \%$ ethanol under an FR1 schedule of reinforcement until a stable baseline of self-administration was reached. The rats were then moved to alcohol vapor chambers and left undisturbed for 3 weeks. At the beginning of the fourth week of vapor exposure, the rats were subjected to an FR1 alcohol self-administration session $8 \mathrm{~h}$ into withdrawal, when blood alcohol levels were negligible. When the escalation of alcohol self-administration was established, the animals underwent stereotaxic surgery for bilateral cannula implantation in the CeA. After 1 week of postsurgical recovery, the rats were returned to the selfadministration chambers to restore their previous baseline levels of ethanol self-administration. The animals were then divided into two groups that were matched according to lever presses for alcohol and injected bilaterally with Daun02 $(2 \mu \mathrm{g} / 0.5 \mu \mathrm{l} /$ site $)$ or its vehicle $90 \mathrm{~min}$ before the self-administration session. Lever pressing for ethanol and water was recorded in five self-administration sessions. Withdrawal signs were scored immediately before the last session. On day 11 , the rats were transcardially perfused at the same time as the usual behavioral testing, and their brains were collected for immunohistochemical analysis.

Experiment 3. Effect of inactivation of CeA neuronal ensembles on saccharin self-administration in ethanol-dependent rats. Fos LacZ transgenic rats $(n=12)$ were trained to self-administer $0.04 \%$ saccharin under an FR1 schedule of reinforcement in $30 \mathrm{~min}$ sessions until a stable baseline of self-administration was reached. The animals were then moved to alcohol vapor chambers and left undisturbed for 3 weeks. At the beginning of the fourth week of vapor exposure, the rats were subjected to FR1 saccharin self-administration sessions $8 \mathrm{~h}$ into withdrawal, when blood alcohol levels were negligible. When a stable level of saccharin self-administration was established, the animals underwent stereotaxic surgery for bilateral intra-CeA injections. After 1 week of postsurgical recovery, the rats were returned to the self-administration chambers to restore their previous baseline levels of saccharin self-administration. The animals were then divided into 2 groups that were matched according to lever presses for saccharin and bilaterally injected with Daun02 (2 $\mu \mathrm{g} / 0.5 \mu \mathrm{l} / \mathrm{side}$ ) or its vehicle $90 \mathrm{~min}$ before saccharin selfadministration. Lever presses for saccharin and water were recorded in five self-administration sessions. Withdrawal signs were scored immediately before the last session. On day 11 , the animals were transcardially 
A

3 Weeks

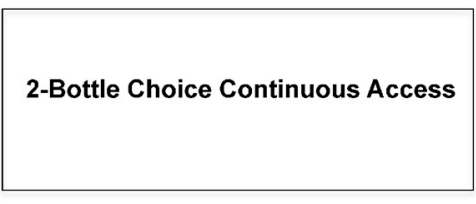

B Alcohol

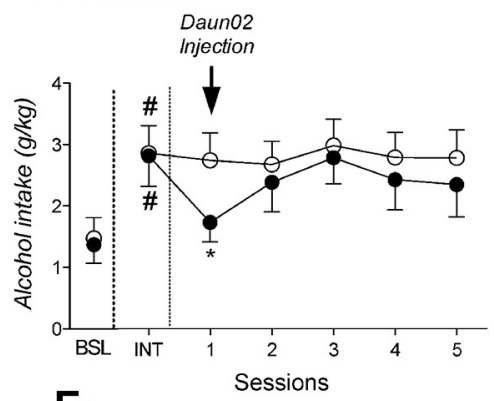

E

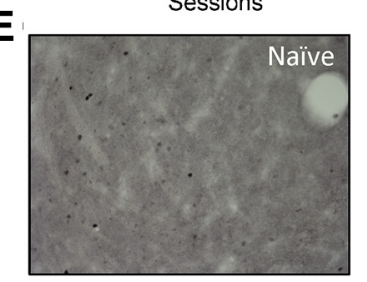

5 Weeks

11 Days

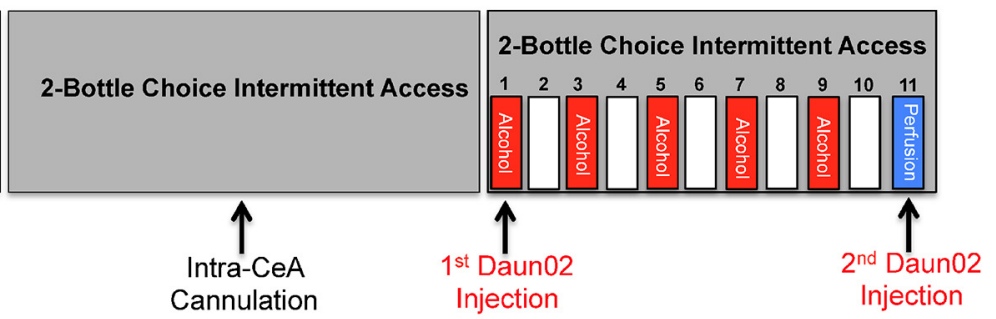

C Water
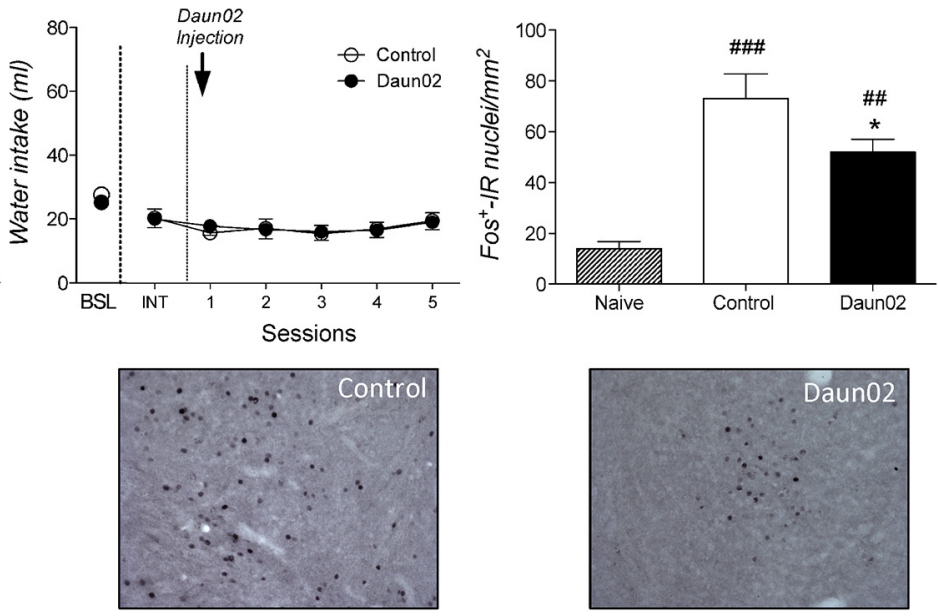

D Fos

Figure 2. Inactivation of CeA neuronal ensembles transiently reduces alcohol intake in nondependent rats. $\boldsymbol{A}$, Experimental design for the effect of inactivation of CeA neuronal ensembles in nondependent rats given intermittent access to $20 \%$ alcohol in their home cages. $\boldsymbol{B}$, Alcohol intake in rats given intermittent access to $20 \%$ alcohol. Animals ( $n=10-11 /$ group) escalated their alcohol intake between the continuous and intermittent phases. Local injection of Daun02 significantly affected alcohol intake only in the first session. No effect was found in the subsequent postinjection sessions. The sessions were conducted every $48 \mathrm{~h}$ so that 7 testing sessions corresponded to 2 weeks. $C$, Water intake was unaffected by the injection of Daun 02 in rats that were given intermittent access to $20 \%$ alcohol. D, Number of Fos + nuclei per square millimeter in the CeA. Animals with intermittent access to alcohol exhibited a significant increase in Fos + neurons in the CeA compared with naive rats. However, the number of Fos + neurons in treated animals was still significantly higher compared with naive rats. ${ }^{*} p<0.05$ versus control (vehicle); \#p $<0.05$ versus baseline drinking before intermittent access (BSL); \#\#p <0.01, \#\#\#p <0.001 versus naive. $\boldsymbol{E}$, Representative $40 \mu \mathrm{m}$ coronal sections of the CeA showing Fos + neurons in naive rats (left), control rats (middle), and Daun02-injected rats (right).

perfused at the same time as the usual behavioral testing, and their brains were collected for immunohistochemical analysis.

\section{Statistical analysis}

The results are expressed as mean \pm SEM. The data were analyzed using two-way ANOVA, with treatment (vehicle or Daun02) as the betweensubjects factor and time (sessions or preescalation and postescalation) as the within-subjects factor. The immunohistochemistry data were analyzed using one-way ANOVA. The ANOVAs were followed by the Newman-Keuls post hoc test when appropriate. Withdrawal signs were analyzed by the nonparametric Mann-Whitney $U$ test. The level of significance was $p \leq 0.05$.

\section{Results}

Experiment 1: effect of inactivation of CeA neuronal ensembles in nondependent rats subjected to intermittent-access $20 \%$ ethanol-drinking paradigm

At the end of the continuous access period, the average alcohol intake was $1.42 \pm 0.22 \mathrm{mg} / \mathrm{kg}$ in $24 \mathrm{~h}$. After intermittent access and stereotaxic surgery for cannula implantation, the new baseline for alcohol intake was $2.82 \pm 0.32 \mathrm{mg} / \mathrm{kg}$ in $24 \mathrm{~h}$. The animals were divided into two groups with comparable levels of escalation of alcohol intake, as confirmed by the ANOVA, which revealed no effect of group $\left(F_{(1,19)}=0.028, p>0.05\right)$, a significant effect of time (continuous and intermittent periods; $F_{(1,19)}=14.92, p<$ $0.001)$, and no group $\times$ time interaction $\left(F_{(1,19)}=0.019, p>\right.$
0.05; Fig. 2A). Water intake did not change between the continuous and intermittent phases, as confirmed by the ANOVA, which revealed no effect of group $\left(F_{(1,19)}=0.37, p>0.05\right)$ or time $\left(F_{(1,19)}=1.58, p>0.05\right)$ and no group $\times$ time interaction $\left(F_{(1,19)}=0.71, p>0.05\right.$; Fig. $\left.2 B\right)$.

Local injection of Daun02 significantly affected alcohol intake, as confirmed by the overall ANOVA, which revealed no effect of treatment $\left(F_{(1,19)}=0.46, p>0.05\right)$, a significant effect of time $\left(F_{(5,19)}=14.92, p<0.01\right)$, and a significant treatment $\times$ time interaction $\left(F_{(5,95)}=2.30, p=0.05\right)$. The Newman-Keuls post hoc test showed that the Daun02 injection reduced alcohol intake only on the first day after the injection $(p<0.01$; Fig. $2 A)$, with no effect on days 2, 3, 4, or 5 after injection. Water intake was unaffected by the injection of Daun02, as confirmed by the ANOVA, which revealed a significant effect of treatment $\left(F_{(1,19)}=0.003, p>0.05\right)$, a significant effect of time $\left(F_{(5,19)}=\right.$ $3.97, p<0.01)$, and no treatment $\times$ time interaction $\left(F_{(5,95)}=\right.$ $2.30, p>0.05$; Fig. $2 B$ ).

Because the effect of treatment lasted only $1 \mathrm{~d}$, we reinjected Daun02 or its vehicle at the end of the experiment, and brains were collected for the evaluation of Fos + cells in the CeA. Rats that were given intermittent access to alcohol exhibited a significant increase in Fos + neurons in the CeA compared with naive rats $\left(F_{(2,21)}=13.75\right.$, 

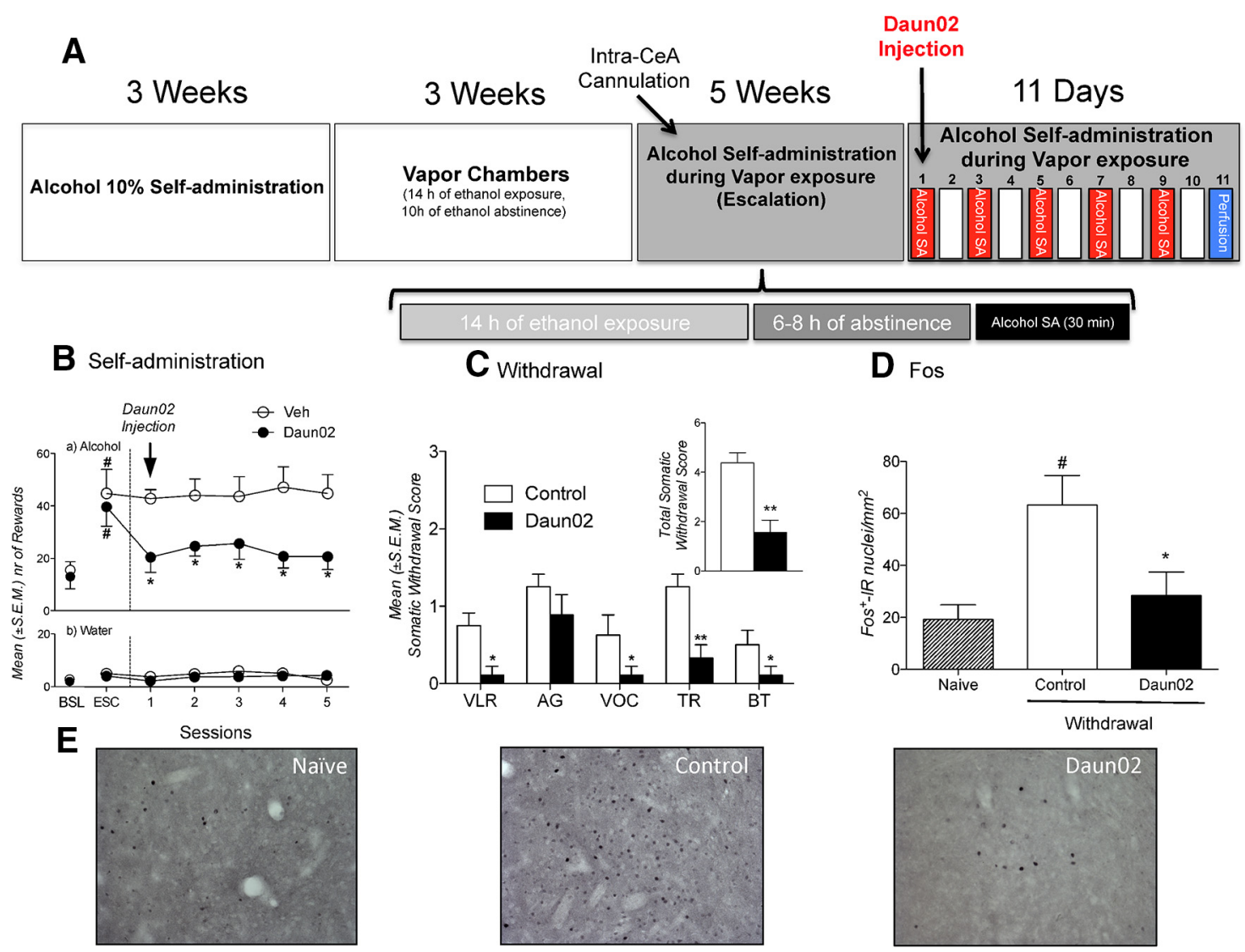

Figure 3. Inactivation of CeA neuronal ensembles reverses escalation of alcohol intake in alcohol-dependent rats. $A$, Experimental design for the effect of inactivation of CeA neuronal ensembles in dependent rats. $\boldsymbol{B}$, Effect of Daun02 injection on alcohol (top) and water (bottom) self-administration in dependent rats. The animals ( $n=8-9 /$ group) escalated their alcohol intake after vapor exposure. Local injection of Daun02 significantly decreased alcohol self-administration. Water self-administration was unaffected by the injection of Daun02. The 30 min drinking sessions were conducted every $48 \mathrm{~h}$ so that 6 sessions corresponded to 2 weeks. ${ }^{*} p<0.05$ versus control (vehicle); $\# p<0.05$ versus baseline before vapor. C, Somatic withdrawal signs measured in session 5 . Inset, Overall withdrawal severity (sum of somatic withdrawal scores across the five behavioral signs of alcohol withdrawal). ${ }^{*} p<0.05,{ }^{* *} p<0.01$ versus control (vehicle). D, Number of Fos + nuclei per square millimeter in the CeA. ${ }^{* * *} p<0.01$ versus control (vehicle); \#\#\#p<0.001 versus naive. $\boldsymbol{E}$, Representative $40 \mu \mathrm{m}$ coronal sections of the CeA showing Fos + neurons in naive rats (left), control rats (middle), and Daun02-injected rats (right).

$p<0.001)$. The Newman-Keuls post hoc test showed that the injection of Daun02 reduced the number of Fos + neurons in the CeA $(p<0.05)$. However, the number of Fos + cells in the treated animals was still significantly higher compared with naive rats $(p<$ 0.01; Fig. 2D).

\section{Experiment 2: effect of inactivation of CeA neuronal ensembles in ethanol-dependent rats}

At the end of the self-administration training, the number of reinforced responses for alcohol was $14.82 \pm 2.17$. After vapor exposure, the animals escalated their level of alcohol intake to an average of $37.94 \pm 4.88$ responses. The animals were divided into two groups with comparable levels of escalation of alcohol intake, as confirmed by the ANOVA, which revealed no effect of group $\left(F_{(1,15)}=0.026, p>0.05\right)$, a significant effect of time (prevapor and postvapor; $\left.F_{(1,15)}=19.51, p<0.001\right)$, and no group $\times$ time interaction $\left(F_{(1,15)}=0.222, p>0.05\right.$; Fig. $\left.3 A\right)$. Water selfadministration did not change between the prevapor and postvapor phases, as confirmed by the ANOVA, which revealed no effect of group $\left(F_{(1,15)}=0.54, p>0.05\right)$ or time $\left(F_{(1,15)}=3.69\right.$, $p>0.05)$ and no group $\times$ time interaction $\left(F_{(1,15)}=0.048, p>\right.$ 0.05 ; Fig. $2 B)$. At this point, the animals were injected with Daun02 or its vehicle in the CeA. Local injection of Daun02 significantly affected alcohol self-administration, as confirmed by the overall ANOVA, which revealed significant effects of treat- ment $\left(F_{(1,15)}=7.59, p<0.05\right)$ and time $\left(F_{(5,15)}=2.50, p<0.05\right)$ and a significant treatment $\times$ time interaction $\left(F_{(5,75)}=2.55, p<\right.$ 0.05). The Newman-Keuls post hoc test showed that the Daun02 injection reduced alcohol intake over the 5 successive sessions $(p<0.01$; Fig. $3 A)$. Water self-administration was unaffected by the Daun02 injection, as confirmed by the ANOVA, which revealed no effect of treatment $\left(F_{(1,15)}=0.32, p>0.05\right)$ or time $\left(F_{(5,15)}=0.76, p>0.05\right)$ and no treatment $\times$ time interaction $\left(F_{(5,75)}=0.61, p>0.05\right.$; Fig. $\left.3 B\right)$.

Immediately before the last alcohol self-administration session, the rats were observed for withdrawal signs. As shown in Figure $3 C$, the control group exhibited significant increases in ventromedial limb retraction (Mann-Whitney $U=13.00, p<$ 0.05 ), tail rigidity (Mann-Whitney $U=9.000, p<0.01$ ), vocalization (Mann-Whitney $U=17.00, p<0.05$ ), and body tremors (Mann-Whitney $U=18.00, p<0.05$ ). The sum of the five rating scores revealed a significant increase in overall withdrawal severity (Mann-Whitney $U=7.0, p<0.01$; Fig. $3 C$, inset).

Two days after the last self-administration session, brains were collected for the evaluation of Fos + cells in the CeA. The ANOVA revealed a significant increase in Fos + neurons after withdrawal from alcohol $\left(F_{(2,20)}=5.731, p<0.05\right)$. The Newman-Keuls post hoc test showed that alcohol-dependent rats had a higher number of Fos + neurons compared with the naive group $(p<0.05$, Daun02 vs controls; Fig. 3D). This effect was completely blocked in animals that 
A
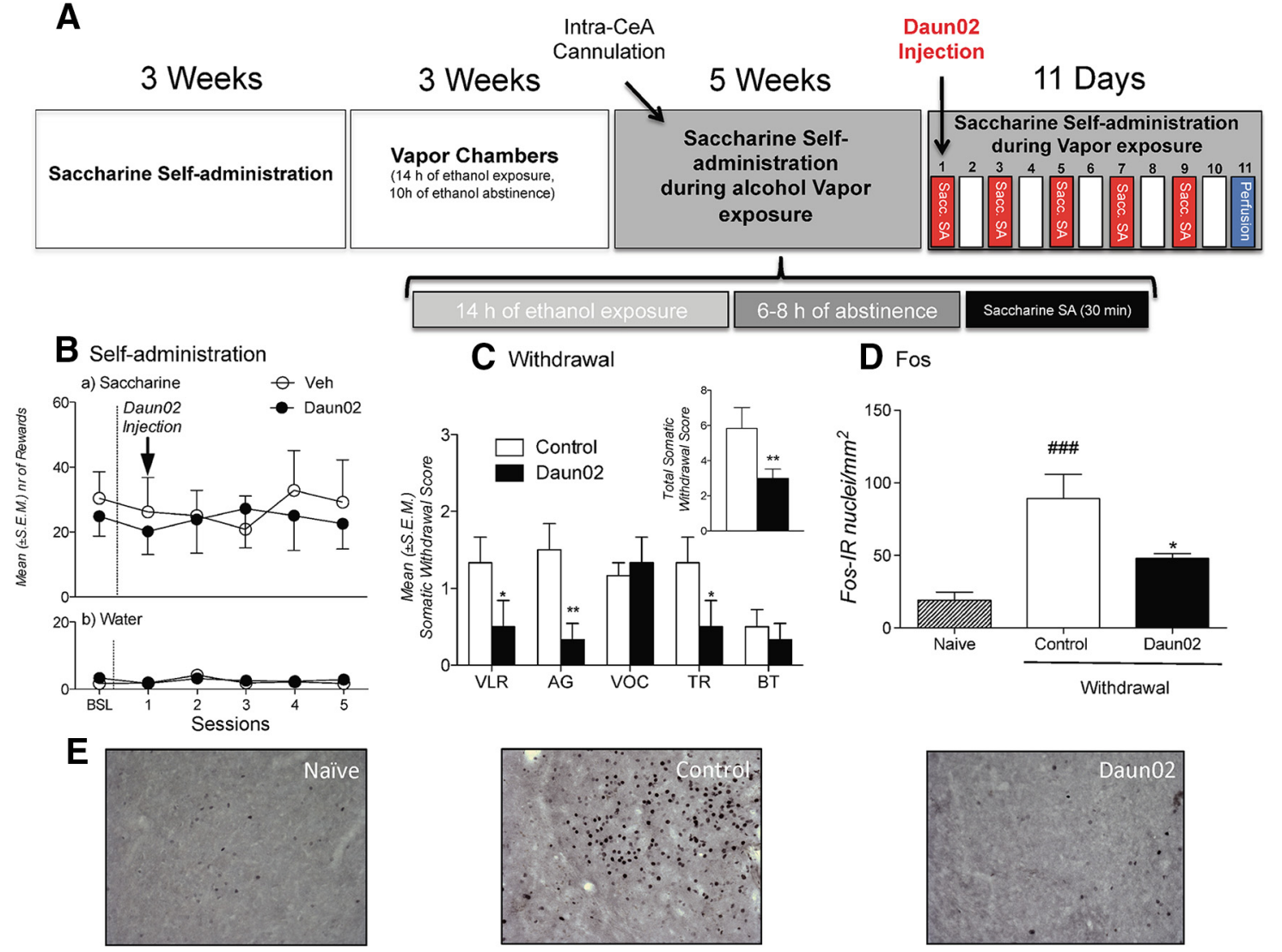

Figure 4. A, Experimental design for the effect of inactivation of CeA neuronal ensembles on saccharin self-administration in dependent rats $(n=6 /$ group). $\boldsymbol{B}$, Saccharin self-administration was unaffected by the injection of Daun02. Water intake was unaffected by the Daun02 injection. The $30 \mathrm{~min}$ drinking sessions were conducted every $48 \mathrm{~h}$ so that 6 sessions corresponded to 2 weeks. C, Somatic withdrawal signs measured in session 5 . Inset, Overall withdrawal severity (sum of somatic withdrawal scores across the five behavioral signs of alcohol withdrawal). ${ }^{*} p<0.05,{ }^{* *} p<$ 0.01 versus control (vehicle). $\boldsymbol{D}$, Number of Fos + nuclei per square millimeter in the CeA. ${ }^{* * *} p<0.01$ versus control (vehicle); \#\#\# $<0.001$ versus naive. E, Representative $40 \mu \mathrm{m}$ coronal sections of the CeA showing Fos + neurons in naive rats (left), control rats (middle), and Daun02-injected rats (right).

were injected with Daun02, in which the number of Fos + neurons was comparable to naive rats $(p>0.05$; Fig. $3 D)$.

\section{Experiment 3: effect of inactivation of CeA neuronal ensembles on saccharin self-administration in ethanol-dependent rats}

At the end of saccharin self-administration training, the average number of reinforced responses was $33.3 \pm 10.19$. After vapor exposure, the animals were divided into two groups that had comparable levels of saccharin self-administration and injected with Daun02 or its vehicle. The mixed factorial ANOVA revealed that saccharin self-administration was unaffected by the injection of Daun02. The statistical analysis did not indicate any effects of treatment $\left(F_{(1,10)}=0.085, p>0.05\right)$ or time $\left(F_{(5,10)}=0.30, p>\right.$ $0.05)$ and no treatment $\times$ time interaction $\left(F_{(5,50)}=0.42, p>\right.$ 0.05; Fig. $4 A$ ). Water intake was also unaffected by the Daun02 injection, as confirmed by the ANOVA, which revealed no effects of treatment $\left(F_{(1,10)}=0.213, p>0.05\right)$ or time $\left(F_{(5,10)}=2.697\right.$, $p>0.05)$ and no treatment $\times$ time interaction $\left(F_{(5,50)}=1.45\right.$, $p>0.05$; Fig. $4 B$ ). Immediately before the last saccharin selfadministration session, the rats were observed for withdrawal signs. As shown in Figure 4C, the control group exhibited significant increases in ventromedial limb retraction (Mann-Whitney $U=16.00, p<0.05$ ), abnormal gait (Mann-Whitney $U=9.00$, $p<0.01$ ), and tail rigidity (Mann-Whitney $U=14.000, p<$ $0.05)$. The sum of the five rating scores revealed a significant increase in overall withdrawal severity (Mann-Whitney $U=8.0$, $p<0.01$; Fig. $4 C$, inset).

Two days after the last self-administration session, brains were collected for the evaluation of Fos + cells in the CeA. The ANOVA revealed a significant increase in Fos + neurons after withdrawal from alcohol $\left(F_{(2,15)}=5.731, p<0.01\right)$. The Newman-Keuls post hoc test showed that alcohol-dependent rats had a higher number of Fos + neurons compared with the naive group ( $p<0.001$, Daun02 vs controls; Fig. $4 D$ ). This effect was blocked in animals that were injected with Daun02, in which the number of Fos + neurons was comparable to naive rats $(p>0.05)$.

\section{Discussion}

The present study tested the hypothesis that the activation of a neuronal ensemble in the CeA during abstinence is required for excessive alcohol drinking in rats. We found that Daun02induced inactivation of an abstinence-related neuronal ensemble in the CeA significantly decreased alcohol drinking in two well established models of drinking in the rat: $24 \mathrm{~h}$ two-bottle choice and dependence-induced drinking.

In the two-bottle choice paradigm, intermittent access to alcohol led to an escalation of alcohol intake that was not observed in rats with continuous access to alcohol (Simms et al., 2008; Carnicella et al., 2014). A single intra-CeA infusion of Daun02 significantly decreased alcohol drinking by $\sim 61 \%$ on the day of 
the infusion (Fig. 2B). The decrease in alcohol drinking was transient, and rats completely recovered their escalated alcohol drinking during the next day of access to alcohol (with no additional Daun02 infusion). No differences were observed in water drinking (Fig. 2C), demonstrating that this effect was selective to alcohol. We also observed a significant decrease ( 29\%) in Fos + neurons in the CeA after the Daun02 infusion compared with the vehicle group (Fig. 2D), confirming the efficacy of Daun02 at the neuronal level. These results parallel previous studies that reported the overactivation of specific neuronal ensembles in the CeA during withdrawal (George et al., 2012; Lee et al., 2015). These data also demonstrate that the recruitment of a neuronal ensemble in the CeA $24 \mathrm{~h}$ into abstinence and immediately before renewed access to alcohol plays a causal role in alcohol-binge-like drinking in rats. However, inhibition of this neuronal ensemble did not permanently decrease excessive alcohol drinking, suggesting that targeting the abstinence-related neuronal ensemble in the CeA may not be an efficient strategy to reverse excessive alcohol drinking in nondependent subjects.

To test the causal role of the abstinence-induced neuronal ensemble in the CeA in alcohol dependence, a second group of rats was trained to self-administer alcohol and made dependent by chronic, intermittent exposure to alcohol vapors (Fig. $3 A$ ). Vapor exposure led to a robust escalation of alcohol drinking when the rats were tested $6-8 \mathrm{~h}$ into abstinence (Fig. $3 \mathrm{Ba}$ ), which is known to reverse both somatic and motivational withdrawal and result in compulsive-like alcohol seeking (Roberts et al., 2000; Vendruscolo et al., 2012). A single infusion of Daun02 $6 \mathrm{~h}$ into abstinence produced a complete normalization of alcohol drinking that lasted at least 2 weeks (Fig. $3 B$ ) and did not affect water self-administration (Fig. $3 \mathrm{Bb}$ ). Moreover, inactivation of the abstinence-related neuronal ensemble in the CeA was associated with a robust decrease in the severity of somatic signs of alcohol withdrawal (Fig. $3 C$ ) despite the fact that the rats were still being exposed to alcohol vapor and reached high blood alcohol levels. Abstinence from alcohol vapor produced a significant recruitment of Fos + neurons in the CeA and Daun02 infusion in the CeA completely prevented this activation (Fig. 3D). These results demonstrate that the recruitment of a neuronal ensemble in the CeA during abstinence from alcohol is required for excessive alcohol drinking that is observed in alcohol-dependent rats and that alcohol drinking in rats in a binge-like model is partially controlled by this same neuronal ensemble.

To test the behavioral specificity of inactivation of this CeA dependence neuronal ensemble, the same experiment was repeated in alcohol-dependent animals that self-administered saccharin (Fig. 4A). Daun02 infusion $6 \mathrm{~h}$ into abstinence from alcohol vapor did not alter saccharin or water self-administration (Fig. $4 B$ ) despite the decrease in the severity of somatic signs of alcohol withdrawal (Fig. 4C) and the robust inhibition of Fos + neurons in the CeA, similar to what was observed in the previous experiment (Fig. 4D). These results demonstrate that an abstinence-related neuronal ensemble is recruited in the CeA after chronic high-dose alcohol, which controls escalated alcohol intake and the expression of somatic signs of alcohol withdrawal without affecting self-administration of a natural reinforcer (i.e., saccharin-sweetened water).

Studies on neuronal ensembles of memory, fear, and addiction have largely focused on the neuronal ensembles that are recruited by cues and contexts and not by an internal state such as abstinence or withdrawal. Indeed, using the Daun02 inactivation method, several groups of investigators have identified neuronal ensembles in the nucleus accumbens that are involved in the context-induced sensitization of cocaine-induced locomotion (Mattson et al., 2008) and in the context-induced reinstatement of cocaine seeking (Cruz et al., 2014). A causal role for such neuronal ensembles was also demonstrated in the medial prefrontal cortex for the context-induced reinstatement of heroin seeking (Bossert et al., 2011) and in the orbitofrontal cortex for the incubation of heroin craving (Fanous et al., 2012). Pfarr et al. (2015) recently identified a neuronal ensemble in the infralimbic cortex that inhibits the cue-induced reinstatement of alcohol seeking. The present study uniquely characterized a neuronal ensemble that is not recruited by a cue or context, but rather by an internal state (i.e., alcohol withdrawal).

The present study demonstrates that a long-lasting reversal of the behavioral and neuronal effects of alcohol dependence can be obtained by specifically targeting an abstinence-related neuronal ensemble in the CeA in dependent rats. Such complete and longlasting reversal of dependence-induced drinking and somatic signs of withdrawal is usually reported with the chronic administration of pharmacological compounds (Steensland et al., 2007; Czachowski and Delory, 2009; Ciccocioppo et al., 2014). Indeed, the present results can be argued to parallel the elegant work by Naqvi et al. (2007) that was performed in humans, demonstrating a complete reversal of nicotine dependence (both somatic and motivational) after brain damage to the insula, in which patients stated that their "body forgot the urge to smoke." We hypothesize that a similar mechanism may be engaged here and that the abstinence-related neuronal ensemble in the CeA may be required for encoding the negative reinforcement that drives compulsive alcohol drinking. This is particularly compelling when considering the prominent connections between the insula and CeA (McDonald et al., 1999) and considering that the CeA plays a key role in the aversive symptoms associated with alcohol withdrawal.

In summary, the present study demonstrates that the recruitment of a neuronal ensemble in the CeA during abstinence from alcohol is causally related to excessive alcohol drinking in alcohol-dependent rats, whereas a similar neuronal ensemble only partially contributes to alcohol-binge-like drinking in nondependent rats. These results identify a critical neurobiological mechanism that is required for alcohol dependence, suggesting that targeting dependence neuronal ensembles may lead to a better understanding of the etiology of alcohol use disorders, with implications for diagnosis, prevention, and treatment.

\section{References}

Barak S, Liu F, Ben Hamida S, Yowell QV, Neasta J, Kharazia V, Janak PH, Ron D (2013) Disruption of alcohol-related memories by mTORC1 inhibition prevents relapse. Nat Neurosci 16:1111-1117. CrossRef Medline

Bossert JM, Stern AL, Theberge FR, Cifani C, Koya E, Hope BT, Shaham Y (2011) Ventral medial prefrontal cortex neuronal ensembles mediate context-induced relapse to heroin. Nat Neurosci 14:420-422. CrossRef Medline

Carnicella S, Ron D, Barak S (2014) Intermittent ethanol access schedule in rats as a preclinical model of alcohol abuse. Alcohol 48:243-252. CrossRef Medline

Ciccocioppo R, Stopponi S, Economidou D, Kuriyama M, Kinoshita H, Heilig M, Roberto M, Weiss F, Teshima K (2014) Chronic treatment with novel brain-penetrating selective NOP receptor agonist MT-7716 reduces alcohol drinking and seeking in the rat. Neuropsychopharmacology 39: 2601-2610. CrossRef Medline

Cruz FC, Koya E, Guez-Barber DH, Bossert JM, Lupica CR, Shaham Y, Hope BT (2013) New technologies for examining the role of neuronal ensembles in drug addiction and fear. Nat Rev Neurosci 14:743-754. CrossRef Medline

Cruz FC, Babin KR, Leao RM, Goldart EM, Bossert JM, Shaham Y, Hope BT (2014) Role of nucleus accumbens shell neuronal ensembles in context- 
induced reinstatement of cocaine-seeking. J Neurosci 34:7437-7446. CrossRef Medline

Czachowski CL, Delory MJ (2009) Acamprosate and naltrexone treatment effects on ethanol and sucrose seeking and intake in ethanol-dependent and nondependent rats. Psychopharmacology 204:335-348. CrossRef Medline

Engeln M, Bastide MF, Toulmé E, Dehay B, Bourdenx M, Doudnikoff E, Li Q, Gross CE, Boué-Grabot E, Pisani A, Bezard E, Fernagut PO (2016) Selective inactivation of striatal FosB/DeltaFosB-expressing neurons alleviates L-dopa-induced dyskinesia. Biol Psychiatry 79:354-361. CrossRef Medline

Fanous S, Goldart EM, Theberge FR, Bossert JM, Shaham Y, Hope BT (2012) Role of orbitofrontal cortex neuronal ensembles in the expression of incubation of heroin craving. J Neurosci 32:11600-11609. CrossRef Medline

George O, Sanders C, Freiling J, Grigoryan E, Vu S, Allen CD, Crawford E, Mandyam CD, Koob GF (2012) Recruitment of medial prefrontal cortex neurons during alcohol withdrawal predicts cognitive impairment and excessive alcohol drinking. Proc Natl Acad Sci U S A 109:1815618161. CrossRef Medline

Gilpin NW, Herman MA, Roberto M (2015) The central amygdala as an integrative hub for anxiety and alcohol use disorders. Biol Psychiatry 77:859-869. CrossRef Medline

Hebb DO (1949) The organization of behavior: a neuropsychological theory. New York: Wiley.

Johnson BA (2008) Update on neuropharmacological treatments for alcoholism: scientific basis and clinical findings. Biochem Pharmacol 75: 34-56. CrossRef Medline

Koob GF (2009) Brain stress systems in the amygdala and addiction. Brain Res 1293:61-75. CrossRef Medline

Koob GF, Volkow ND (2010) Neurocircuitry of addiction. Neuropsychopharmacology 35:217-238. CrossRef Medline

Koob GF, Buck CL, Cohen A, Edwards S, Park PE, Schlosburg JE, Schmeichel B, Vendruscolo LF, Wade CL, Whitfield TW Jr, George O (2014) Addiction as a stress surfeit disorder. Neuropharmacology 76:370-382. CrossRef Medline

Koya E, Golden SA, Harvey BK, Guez-Barber DH, Berkow A, Simmons DE, Bossert JM, Nair SG, Uejima JL, Marin MT, Mitchell TB, Farquhar D, Ghosh SC, Mattson BJ, Hope BT (2009) Targeted disruption of cocaineactivated nucleus accumbens neurons prevents context-specific sensitization. Nat Neurosci 12:1069-1073. CrossRef Medline

Lee KM, Coehlo M, McGregor HA, Waltermire RS, Szumlinski KK (2015) Binge alcohol drinking elicits persistent negative affect in mice. Behav Brain Res 291:385-398. CrossRef Medline

Macey DJ, Schulteis G, Heinrichs SC, Koob GF (1996) Time-dependent quantifiable withdrawal from ethanol in the rat: effect of method of dependence induction. Alcohol 13:163-170. CrossRef Medline

Mattson BJ, Koya E, Simmons DE, Mitchell TB, Berkow A, Crombag HS, Hope BT (2008) Context-specific sensitization of cocaine-induced locomotor activity and associated neuronal ensembles in rat nucleus accumbens. Eur J Neurosci 27:202-212. Medline
McDonald AJ, Shammah-Lagnado SJ, Shi C, Davis M (1999) Cortical afferents to the extended amygdala. Ann N Y Acad Sci 877:309-338. CrossRef Medline

Naqvi NH, Rudrauf D, Damasio H, Bechara A (2007) Damage to the insula disrupts addiction to cigarette smoking. Science 315:531-534. CrossRef Medline

Paxinos G, Watson C (2005) The rat brain in stereotaxic coordinates, Ed 5. Amsterdam: Elsevier Academic.

Pfarr S, Meinhardt MW, Klee ML, Hansson AC, Vengeliene V, Schönig K, Bartsch D, Hope BT, Spanagel R, Sommer WH (2015) Losing control: excessive alcohol seeking after selective inactivation of cue-responsive neurons in the infralimbic cortex. J Neurosci 35:10750-10761. CrossRef Medline

Roberto M, Madamba SG, Stouffer DG, Parsons LH, Siggins GR (2004) Increased GABA release in the central amygdala of ethanol-dependent rats. J Neurosci 24:10159-10166. CrossRef Medline

Roberto M, Cruz MT, Gilpin NW, Sabino V, Schweitzer P, Bajo M, Cottone P, Madamba SG, Stouffer DG, Zorrilla EP, Koob GF, Siggins GR, Parsons LH (2010) Corticotropin releasing factor-induced amygdala gammaaminobutyric acid release plays a key role in alcohol dependence. Biol Psychiatry 67:831-839. CrossRef Medline

Roberts AJ, Heyser CJ, Cole M, Griffin P, Koob GF (2000) Excessive ethanol drinking following a history of dependence: animal model of allostasis. Neuropsychopharmacology 22:581-594. CrossRef Medline

Santone KS, Oakes SG, Taylor SR, Powis G (1986) Anthracycline-induced inhibition of a calcium action potential in differentiated murine neuroblastoma cells. Cancer Res 46:2659-2664. Medline

Simms JA, Steensland P, Medina B, Abernathy KE, Chandler LJ, Wise R, Bartlett SE (2008) Intermittent access to $20 \%$ ethanol induces high ethanol consumption in Long-Evans and Wistar rats. Alcohol Clin Exp Res 32:1816-1823. CrossRef Medline

Steensland P, Simms JA, Holgate J, Richards JK, Bartlett SE (2007) Varenicline, an alpha4beta2 nicotinic acetylcholine receptor partial agonist, selectively decreases ethanol consumption and seeking. Proc Natl Acad Sci U S A 104:12518-12523. CrossRef Medline

Vendruscolo LF, Roberts AJ (2014) Operant alcohol self-administration in dependent rats: focus on the vapor model. Alcohol 48:277-286. CrossRef Medline

Vendruscolo LF, Barbier E, Schlosburg JE, Misra KK, Whitfield TW Jr, Logrip ML, Rivier C, Repunte-Canonigo V, Zorrilla EP, Sanna PP, Heilig M, Koob GF (2012) Corticosteroid-dependent plasticity mediates compulsive alcohol drinking in rats. J Neurosci 32:7563-7571. CrossRef Medline

Weiner JL, Valenzuela CF (2006) Ethanol modulation of GABAergic transmission: the view from the slice. Pharmacol Ther 111:533-554. CrossRef Medline

Wrase J, Makris N, Braus DF, Mann K, Smolka MN, Kennedy DN, Caviness VS, Hodge SM, Tang L, Albaugh M, Ziegler DA, Davis OC, Kissling C, Schumann G, Breiter HC, Heinz A (2008) Amygdala volume associated with alcohol abuse relapse and craving. Am J Psychiatry 165:1179-1184. CrossRef Medline 